\title{
PROGRAMA MAIS MÉDICOS: LIMITES E POTENCIALIDADES
}

\author{
PROGRAMA MAIS MÉDICOS: LIMITS AND POSSIBILITIES
}

Sandra Mara Maciel-Lima

Doutora em Sociologia pela UFPR. Pesquisadora Docente do Mestrado em Direito do Centro Universitário Curitiba. E-mail: maciellima.sandra@gmail.com

Marisete Teresinha Hoffmann-Horochovski

Doutora em Sociologia. Pesquisadora Docente do Programa Pós-Graduação em Desenvolvimento Territorial Sustentável da Universidade Federal do Paraná.

E-mail: marisetehh@gmail.com

José Miguel Rasia

Professor do Programa de Pós-Graduação em Sociologia da Universidade Federal do Paraná. E-mail: zecarasia@gmail.com

Convidados

Doi: $10.5585 /$ rdb.v17i7.644

RESUMO: Busca-se neste artigo mapear as condições da criação do Programa Mais Médicos e por meio de revisão sistemática de artigos publicados em periódicos indexados no SCIELO e BIREME, localizar o debate gerado pelo programa. Os limites apontados pelos autores pesquisados demonstram certa preocupação com a repercussão destas medidas a longo prazo, tanto no que diz respeito à formação e contratação dos médicos, como no suporte financeiro que o Programa exige. As potencialidades, por sua vez, passam pela valorização de políticas governamentais preocupadas em efetivar medidas que assegurem a ampliação e a garantia de médicos generalistas para a Atenção Básica, em áreas deficitárias. Por fim, o confronto das potencialidades do Programa Mais Médicos e de seus limites pode contribuir com o processo de avaliação deste Programa de Governo, que visa, em linhas gerais, melhorar o atendimento primário na saúde pública brasileira.

Palavras-Chave: Atenção Básica. Sistema Único de Saúde. Formação em saúde. Política Pública.

ABSTRACT: In this paper we search for mapping the conditions of its creation and through systematic review of articles published in journals indexed in SCIELO and BIREME databases, to locate the debate generated by the program. The limits indicated by the authors surveyed show some concern about the repercussion of these long-term measures, both as regards the training and hiring of physician, and the financial support the program requires. The potentiabilities, in turn, pass the valuation of government policies concerned in to apply measures to ensure the expansion and to ensure general physician for Primary Care in deficit areas. Finally, the comparison of the potentiability Mais Médicos Program and their boundaries can contribute to 
the assessment process of this government program, which aims, in genera to improve primary care in the Brazilian public health.

Keywords: Primary Care. Sistema Único de Saúde. health education. Public policy

SUMÁRIO: Introdução, 1; O Programa Mais Médicos; Limites e Potencialidades do Programa Mais Médicos; Considerações Finais; Referências Bibliográficas.

\section{INTRODUÇÃO}

A falta de médicos nos serviços públicos de saúde faz parte da realidade brasileira e foi sempre o motivo predominante das críticas ao funcionamento do Sistema Único de Saúde (SUS). A demora no atendimento na Atenção Básica (Primária) desdobra-se em prejuízos imediatos aos doentes, principalmente para os que necessitam atendimento de mais Alta Complexidade. Se, por um lado, o sistema de referenciação da atenção à saúde, instituído pelo SUS, criou uma rede de hospitais especializados em atendimentos de média e alta complexidade e racionalizou a busca por esses níveis de atenção, a falta de médicos atuando na Atenção Básica configurou-se como o principal entrave para o bom funcionamento do Sistema. Mesmo tendo como princípio o atendimento integral à saúde, o SUS se debate com a lentidão dos atendimentos na Atenção Básica e seus desdobramentos.

Nesse sentido, visando combater as desigualdades de acesso à Atenção Básica, o Governo implementou em 2013 o Programa Mais Médicos (PMM), tendo como mote "Mais médicos para o Brasil, mais saúde para você" (BRASIL, 2014). O Programa foi estruturado em três eixos principais: investimento na melhoria da infraestrutura das Unidades Básicas de Saúde (UBS); ampliação e reformas educacionais dos cursos de graduação em medicina e residência médica no país; e a provisão emergencial de médicos em áreas vulneráveis, denominado justamente de Projeto Mais Médicos para o Brasil (OLIVEIRA et al., 2015).

A implantação do Programa, contudo, gerou muita polêmica. Políticos da oposição, organizações de classe e associações médicas, estudantes de medicina e parte da mídia se manifestaram contra, fazendo duras críticas à qualidade dos médicos e as formas de contrato instituídas pelo PMM. Os médicos estrangeiros foram alvos de ataques e repúdio; uma rápida busca nos jornais, revistas e programas de TV nos dão a dimensão dessas manifestações, que se iniciaram com o anúncio do Programa pelo Governo Federal e continuaram durante o primeiro ano de seu funcionamento.

Apesar do Ministério da Saúde apresentar dados de que o Programa possibilitou em um ano a inserção de 14.462 médicos na Atenção Básica, sendo 75\% destes alocados em municípios de alta vulnerabilidade (BRASIL, 2015a), as críticas ainda são inúmeras.

Destarte, este artigo tem por intuito analisar este Programa, destacando seus limites e potencialidades em relação ao atendimento aos usuários do SUS. Para tanto, se debruça sobre a legislação que institui o PMM e os dados que resultam de uma revisão bibliográfica sistemática dos artigos científicos publicados e constantes nas bases de dados eletrônicas SCIELO e BIREME. Não serão analisados artigos, notícias e opiniões veiculados pela mídia.

A revisão compreende os artigos constantes dessas bases no período de julho de 2013 a outubro de 2015. Através das palavras-chave "programa mais médicos" e "mais médicos", pela estratégia de busca inicial localizamos dezesseis artigos, frutos de pesquisas realizadas após a publicação da Medida Provisória 621/2013 (BRASIL, 2013a), e da Lei n. ${ }^{\circ}$ 12.871/2013 (BRASIL, 2013b). Dos dezesseis artigos, selecionamos nove que julgamos pertinentes à discussão.

Na primeira parte apresentamos dados da relação médico/habitantes no Brasil e o PMM a partir da MP e da Lei que o instituiu, e na sequência destacamos seus limites e potencialidades 
na perspectiva dos trabalhos e autores selecionados. Por fim, traçamos considerações finais sobre o PMM e suas controvérsias.

\section{O PROGRAMA MAIS MÉDICOS}

A carência e a má distribuição geográfica de profissionais de saúde, especialmente médicos e enfermeiros, é uma situação recorrente ao longo do tempo em diversos países. A situação do Brasil, segundo Campos, Machado e Girard (2009), não é muito diferente que a de países mais ricos.

Quando observamos os dados da Tabela 1, percebemos que houve um aumento absolutamente importante no número de médicos com registro profissional no Brasil. Entre as décadas de 1980 a 2010, este número mais que dobrou. Embora isso interfira positivamente na relação médico/habitante, há concentração da população médica.

Os dados mais importantes desse quadro dizem respeito às décadas compreendidas entre 1950 e 2010. Na década de 1950 o esforço para transformar o Brasil num país moderno e industrializado, resultou no crescimento da população urbana. A partir daí a demanda por serviços como educação e saúde sofre seu mais significativo aumento, em que pesem às desigualdades de acesso a estes serviços.

TABELA 1 - POPULAÇÃO TOTAL E MÉDICA NO BRASIL - 1910/2010

\begin{tabular}{ccc}
\hline Década & População & Médicos \\
\hline 1910 & 23.414 .177 & 13.270 \\
1920 & 30.635 .605 & 14.031 \\
$1930^{(1)}$ & - & 15899 \\
1940 & 41.165 .289 & 20.745 \\
1950 & 51.941 .767 & 26.120 \\
1960 & 70.070 .457 & 34.792 \\
1970 & $93.139 . .037$ & 58.994 \\
1980 & 119.002 .706 & 137.347 \\
$1991^{(2)}$ & 146.002 .706 & 219.084 \\
2000 & 169.799 .926 & 291.926 \\
2010 & 190.732 .694 & 364.757 \\
\hline
\end{tabular}

Fonte: IBGE Censos Demográficos e CFM/CREMESP. Demografia Médica (2011, p. 16) Obs.: (1) No ano de 1930 por motivos políticos o Censo não foi realizado. (2) Os Dados da População correspondem ao Censo que por problemas técnicos foi realizado em 1991.

Segundo dados da Demografia Médica, de 1940 a 1970, o número de médicos no Brasil aumentou $184,4 \%$, enquanto a população cresceu $126,2 \%$ e com a abertura de novas vagas nas Escolas de Medicina a partir dos anos 70, até 2010 houve um aumento de 394,8\% enquanto a população cresceu $82,3 \%$ na primeira década do século XXI, o percentual de médicos cresceu 21,3\% (DEMOGRAFIA, 2011, p. 16).

Os dados apresentados revelam um crescimento dos médicos bem superior ao crescimento da população. Porém, a questão é outra. A desigualdade de acesso ao atendimento na Atenção Básica, não repousa somente na relação médicos/habitantes, mas sim em mais outros três fatores: as especialidades, a distribuição espacial e a fixação dos médicos em cidade de pequeno porte.

A Demografia Médica de 2015 (SCHEFFER et al., 2015, p. 21) mostra que as capitais das 27 unidades da federação concentram 23,80\% da população e 55,24\% dos registros de médicos. O interior, por sua vez, possui 76,2\% da população total e 44,76\% dos médicos. Assim, 
as capitais apresentam uma taxa de 4,84 médicos por 1.000 habitantes (Tabela 2), já no interior esta taxa é de 1,23 médicos por 1.000 habitantes (Tabela 3). Também há desigualdades entre as capitais, Rio Branco, capital do Acre, tem 2,03 médicos por 1.000 habitantes - a menor razão entre as capitais -, enquanto Vitória (ES) possui a maior taxa, 11,9, por habitante (Tabela 2).

TABELA 2- DISTRIBUIÇÃO DE MÉDICOS, SEGUNDO CAPITAIS E GRANDES REGIÕES-BRASIL-2014

\begin{tabular}{|c|c|c|c|}
\hline Capitais & População & Médicos & Médico/1.000 habitantes \\
\hline Aracaju & 614.577 & 3.180 & 5,17 \\
\hline Belém & 1.425 .922 & 5.333 & 3,74 \\
\hline Belo Horizonte & $2.479,165$ & 16.739 & 6,75 \\
\hline Boa Vista & 308.996 & 657 & 2,13 \\
\hline Brasília & 2.789 .761 & 8.299 & 2,97 \\
\hline Campo Grande & 832.352 & 2.900 & 3,48 \\
\hline Cuiabá & 569,830 & 2.279 & 4,00 \\
\hline Curitiba & 1.848 .946 & 10.738 & 5,81 \\
\hline Florianópolis & 453.285 & 3.604 & 7,95 \\
\hline Fortaleza & 2.551 .806 & 8.684 & 3,40 \\
\hline Goiânia & 1.393 .575 & 7.915 & 5,68 \\
\hline João Pessoa & 769.607 & 4.291 & 5,58 \\
\hline Macapá & 437.256 & 621 & 1,42 \\
\hline Maceió & 996.733 & 3.987 & 4,00 \\
\hline Manaus & 1.982 .177 & 4.123 & 2,08 \\
\hline Natal & 853.928 & 3.808 & 4,46 \\
\hline Palmas & 257.904 & 840 & 3,26 \\
\hline Porto Alegre & 1.467 .816 & 13.068 & 8,90 \\
\hline Porto Velho & 484,992 & 1283 & 2,65 \\
\hline Recife & 1.599 .513 & 10.360 & 6,48 \\
\hline Rio Branco & 357.194 & 726 & 2,03 \\
\hline Rio de Janeiro & 6.429 .923 & 40.378 & 6,28 \\
\hline Salvador & 2.883 .682 & 11.582 & 4,02 \\
\hline São Luiz & 1.053 .922 & 3.327 & 3,16 \\
\hline São Paulo & 11.821 .873 & 54.978 & 4,65 \\
\hline Teresina & 836.475 & 3.714 & 4,44 \\
\hline Vitória & 348.268 & 4.146 & 11,90 \\
\hline Brasil (Capitais) & 47.849.478 & 231.560 & 4,84 \\
\hline
\end{tabular}

Fonte: SCHEFFER M. et al (2015).

A tabela 3, de acordo com dados de 2014, mostra que as maiores concentrações encontram-se nas capitais do Sudeste e do Sul, com destaque para Vitória, Florianópolis, Belo Horizonte e Porto Alegre. No interior, a distribuição também é desigual e é provável que a maior agregação ocorra nas maiores cidades.

Nesse sentido, mesmo que o Brasil tenha melhorado a relação médico/habitante nas últimas décadas, é importante considerar que:

Esta média geral esconde, no entanto, a existência de extremas desigualdades: ao lado de situações de saturação de médicos nas grandes cidades e regiões mais ricas do país coexistem situações de extrema privação, ao qual são submetidos expressivos contingentes da população do país pela ausência de médicos (CAMPOS, MACHADO e GIRARD, 2009, p. 14). 
TABELA 3 - DISTRIBUIÇÃO DE MÉDICOS, SEGUNDO UNIDADES DA FEDERAÇÃO (EXCETO CAPITAIS) E GRANDES REGIÕES - BRASIL 2014

\begin{tabular}{lccc}
\hline \multicolumn{1}{c}{ UF (Interior)/Região } & Médicos & População & Médico/1.000 habitantes \\
\hline Acre & 1.005 & 1.243 .222 & 0,81 \\
Alagoas & 234 & 2.304 .202 & 0,10 \\
Amazonas & 239 & 1.825 .744 & 0,13 \\
Amapá & 121 & 297.740 & 0,41 \\
Bahia & 7.342 & 12.160 .455 & 0,60 \\
Ceará & 2.359 & 6.226 .770 & 0,38 \\
Distrito Federal & - & - & - \\
Espirito Santo & 4.435 & 3.491 .098 & 1,27 \\
Goiás & 3.880 & 5.040 .473 & 0,77 \\
Mato Grosso & 2.234 & 2.612 .283 & 0,86 \\
Mato G. do Sul & 1.876 & 1.754 .917 & 1,07 \\
Minas Gerais & 27.519 & 18.114 .19 & 1,52 \\
Maranhão & 2.069 & 5.740 .379 & 0,36 \\
Pará & 1.948 & 6.543 .732 & 0,30 \\
Paraíba & 1.634 & 3.144 .814 & 0,52 \\
Paraná & 10.808 & 9.148 .519 & 1,18 \\
Pernambuco & 4.756 & 7.609 .037 & 0,63 \\
Piauí & 23 & 2.347 .691 & 0,01 \\
Rio de Janeiro & 20.968 & 9.939 .256 & 2,11 \\
Rio G. do Norte & 1.242 & 2.520 .031 & 0,49 \\
Rio G. do Sul & 14.351 & 9.696 .227 & 1,48 \\
Rondônia & 1.005 & 1.243 .222 & 0,81 \\
Roraima & 71 & 179.076 & 0,40 \\
Santa Catarina & 10.134 & 6.180 .969 & 1,64 \\
São Paulo & 63.017 & 31.841 .796 & 1,98 \\
Sergipe & 202 & 1.581 .085 & 0,13 \\
\hline Brasil (Interior) & $\mathbf{1 8 4 . 0 1 2}$ & $\mathbf{1 5 3 . 1 8 3 . 2 3 6}$ & $\mathbf{1 , 2 3}$ \\
\hline
\end{tabular}

Fonte: SCHEFFER M. et al. (2015).

Na tentativa de melhorar estes indicadores e como parte de uma série de medidas para combater as desigualdades de acesso à Atenção Básica, o Governo Federal lança o PMM por meio da Medida Provisória 621/2013 (BRASIL, 2013a), como uma resposta parcial às manifestações que se propagaram pelo país no mês de junho e que reivindicavam, entre outras, mais investimentos em saúde e educação.

A Medida Provisória que criou o PMM foi apresentada pela presidente Dilma Rousseff com os então ministros da Saúde e Educação Alexandre Padilha e Aloízio Mercadante. Os ministros aludiram para o caráter intersetorial desta política e anunciaram um trabalho conjunto de seus ministérios com o intuito de aperfeiçoar o atendimento do SUS - propiciando mais médicos para o atendimento básico e melhorias na infraestrutura das Unidades de Saúde e Hospitais Universitários - e aumentar o número de vagas nos cursos de medicina.

Em 22 de outubro de 2013, a MP 621 (BRASIL, 2013a) foi substituída pela Lei n. ${ }^{o}$ 12.871 (BRASIL, 2013b), que institui o PMM com a finalidade de formar recursos humanos na área médica para o SUS, visando, conforme seu Artigo $1^{\circ}$ :

I - diminuir a carência de médicos nas regiões prioritárias para o SUS, a fim de reduzir as desigualdades regionais na área da saúde;

II - fortalecer a prestação de serviços de atenção básica em saúde no país;

III - aprimorar a formação médica no país e proporcionar maior experiência no campo de prática médica durante o processo de formação;

IV - ampliar a inserção do médico em formação nas unidades de atendimento do SUS, desenvolvendo seu conhecimento sobre a realidade de saúde da população brasileira; 
V - fortalecer a política de educação permanente com a integração ensinoserviço por meio da atuação das instituições de educação superior na supervisão acadêmica das atividades desempenhada pelos médicos;

$\mathrm{VI}$ - promover a troca de conhecimentos e experiências entre profissionais da saúde brasileiros e médicos formados em instituições estrangeiras;

VII - estimular a realização de pesquisas aplicadas ao SUS (BRASIL, 2013b).

O PMM busca atender a demanda significativa de médicos, principalmente em municípios do interior e nas periferias de grandes cidades que encontram dificuldades em contrata-los (NUNES, 2014), pois a maioria dos médicos formados no Brasil não demonstra interesse em atuar nessas regiões. Em outros termos, visa atuar na diminuição das desigualdades regionais tão presentes no território brasileiro.

Nesse sentido, a Lei 12.871 (BRASIL, 2013b) prevê em seu Art. $2^{\circ}$ a adoção das seguintes ações:

I - reordenação da oferta de cursos de Medicina e de vagas para residência médica, priorizando regiões de saúde com menor relação de vagas e médicos por habitante e com estrutura de serviços de saúde em condições de ofertar campo de prática suficiente e de qualidade para os alunos.

II - estabelecimento de novos parâmetros para a formação médica no País; e

III - promoção, nas regiões prioritárias do SUS, de aperfeiçoamento de médicos na área de atenção básica em saúde, mediante integração ensino serviço, inclusive por meio de intercâmbio internacional (BRASIL, 2013b).

Para a realização deste Programa o Governo Federal conta com uma articulação de órgãos públicos da saúde e da educação, nos três níveis da organização político-administrativa do país, coordenada, a nível federal, pelos Ministérios da Saúde e da Educação. A nível estadual e municipal conta com a participação e incentivo das Secretarias Estaduais e Municipais de Saúde, assim como, com o apoio das Universidades públicas e privadas (NUNES, 2014).

No que se refere à falta de médicos em algumas regiões do Brasil, mormente interioranas e periféricas, o governo apresentou os dados do diagnóstico que justificaram a elaboração do Programa. No primeiro semestre de 2013, o Brasil possuía 1,83 médicos por mil habitantes, quando o número recomendado pela ONU é de 2,5. Todavia, segundo o próprio governo, o mais grave não é a média em si, mas a distribuição espacial desigual. Vinte e dois estados apresentavam um número inferior à média nacional, sendo que cinco dentre eles possuíam menos de um médico por mil habitantes: Acre, Amapá, Piauí, Pará e Maranhão - este último com 0,58 médicos por mil habitantes apresentava o índice mais baixo registrado em território brasileiro. Já Distrito Federal, Rio de Janeiro, São Paulo, Rio Grande do Sul e Espírito Santo possuíam mais médicos do que a média nacional, embora também houvesse discrepância entre eles. Distrito Federal, com o melhor número, tinha 3,46 médicos por mil habitantes e Espírito Santo 1,97 (BRASIL, 2014).

Com o detalhamento deste quadro, o governo procurou fundamentar sua estratégia de mobilizar profissionais para ocuparem postos em regiões carentes de médicos na Atenção Básica, que é a porta de entrada do SUS e que mais recebe demandas da sociedade. E mais, esclareceu que na falta de profissionais brasileiros para ocuparem as vagas disponíveis, haveria chamadas para que estrangeiros o fizessem (BRASIL, 2013c).

Apesar do PMM ter estabelecido normativas para o preenchimento das mais de treze mil vagas que deveriam ser ocupadas até abril de 2014, a "importação" de médicos estrangeiros, como dissemos, gerou muita polêmica e deu início a inúmeras batalhas, travadas principalmente nos meios de comunicação, entre apoiadores e críticos do Programa. Uma das principais lutas é com o Conselho Federal de Medicina (CFM), que desde o anúncio da Medida Provisória se 
posicionou categoricamente contra o Programa e não tem poupado esforços no sentido de desqualificá-lo. Talvez por isso mesmo, houve pouca adesão de médicos brasileiros ao Programa e muitos assumiram posições hostis à sua implantação. Seus principais argumentos consistiam em: falta de infraestrutura do SUS, baixos salários e isolamento nas pequenas cidades, o que diminui as chances de aprimoramento técnico e dificultava o exercício profissional. Essa pouca adesão aumentou a "importação" de médicos estrangeiros e, por extensão, alimentou ainda mais as polêmicas em torno do Programa.

No que diz respeito à formação médica, o PMM prevê o aumento de vagas em cursos de Medicina e em residência médica e a abertura de novos cursos privados em regiões consideradas prioritárias para o SUS que, evidentemente, deve ter a proposta aprovada pelo Ministério da Educação (MEC) (BAHIA, 2015).

Das vagas criadas em 2015, a maioria delas se concentrou em municípios de até setenta mil habitantes e atendem os seguintes critérios estabelecidos pelo MEC:

a existência de pelo menos cinco leitos do Sistema Único de Saúde (SUS) por aluno, de equipes de atenção básica que comportem três alunos, a presença de leitos de emergência ou pronto-socorro e hospitais de ensino com mais de 100 leitos... Todos os cursos (...) são em municípios que comprovaram essas condições foram seguidos critérios técnicos que orientam a abertura de cursos na rede privada. Há uma unificação do processo de expansão tanto na rede pública quanto na rede privada (GABRIEL, 2015, s/p.).

Os novos cursos e vagas de medicina visam atender as áreas que vem apresentando as maiores deficiências no número de profissionais e uma grande demanda por atendimento: "Clínica Médica, Cirurgia, Ginecologia/Obstetrícia, Pediatria e Medicina de Família e Comunidade" (BRASIL, 2014). Cyrino et al (2015, p. 5) sublinha que a criação dessas vagas, tanto na graduação quanto na especialização, objetiva a "valorização da Atenção Básica, da Estratégia de Saúde da Família e áreas prioritárias para o SUS". Valorização que visa garantir o princípio da universalização do atendimento e, por conseguinte, a diminuição das desigualdades regionais.

De forma geral, não houve grandes polêmicas com relação a esse quesito, pensadas a médio e longo prazo. A exceção foi a inclusão de um segundo ciclo nos cursos de Medicina, no qual os estudantes atuariam por dois anos no Sistema Único de Saúde, em contato direto com os usuários, tal como detalhado nos artigos 4 e 5 da Medida Provisória 621/2013 (BRASIL, 2013a).

Art. $4^{\circ}$ - Para os ingressantes nos cursos de medicina a partir de $1^{\circ}$ de janeiro de 2015, a formação do médico abrangerá dois ciclos distintos e complementares entre si, correspondendo:

I - o primeiro ciclo, à observância das diretrizes curriculares nacionais, com o cumprimento da carga horária não inferior a sete mil e duzentas horas; e

II - o segundo ciclo, a treinamento em serviço, exclusivamente na atenção básica à saúde no âmbito do SUS, com duração mínima de dois anos, conforme regulamentação do Conselho Nacional de Educação - CNE, homologada pelo Ministro de Estado da Educação [...]

Art. $5^{\circ}$ - Ao estudante de medicina aprovado no primeiro ciclo, conforme certificado expedido pela correspondente instituição de educação superior, será concedida permissão para o exercício profissional da medicina, válida exclusivamente para as atividades do segundo ciclo de formação.

$\S 1^{\circ} \mathrm{A}$ inscrição no segundo ciclo de formação é condição necessária e suficiente para expedição da permissão de exercício profissional de que trata o caput pelos Conselhos Regionais de Medicina. 
A recepção, por assim dizer, do chamado segundo ciclo não foi nada calorosa, até porque aumentaria em dois anos a formação do médico brasileiro. Esse foi um dos poucos pontos em que o governo estrategicamente recuou. A Lei 12.871, traz um texto bem diferente.

Art. $4^{\circ}$. O funcionamento dos cursos de Medicina é sujeito à efetiva implantação das diretrizes curriculares nacionais definidas pelo Conselho Nacional de Educação (CNE).

$\S 1^{\circ}$ Ao menos $30 \%$ (trinta por cento) da carga horária do internato médico na graduação serão desenvolvidos na Atenção Básica e em Serviço de Urgência e Emergência do SUS, respeitando-se o tempo mínimo de 2 (dois) anos de internato, a ser disciplinado nas diretrizes curriculares nacionais. [...]

Art. $5^{\circ}$. Os Programas de Residência Médica de que trata a Lei ${ }^{\circ}$ 6.932, de 7 de julho de 1981, ofertarão anualmente vagas equivalentes ao número de egressos dos cursos de graduação em Medicina do ano anterior.

Parágrafo único. A regra de que trata o caput é meta a ser implantada progressivamente até 31 de dezembro de 2018 (BRASIL, 2013b).

O segundo ciclo foi eliminado menos de um mês após a edição da Medida Provisória. Todavia, a atuação do estudante na Atenção Básica e em Serviços de Urgência e Emergência do SUS foi garantida por lei e estabelecida em no mínimo $30 \%$ da carga horária do internato médico na graduação. Essa mudança atenuou conflitos e aumentou a receptividade de diferentes setores da sociedade para com o PMM.

Por fim, é mister sublinhar que o governo federal propôs também investimentos para a melhoria de infraestrutura e construção de Unidades Básicas de Saúde (UBS), Unidades de Pronto Atendimento (UPAs) e Hospitais Universitários (HU). A perspectiva governamental é de que essas ações em conjunto alterariam significativamente o cenário da saúde pública no Brasil, propiciando mais saúde para a população.

Dito isso, precisamos nos deter um pouco na operacionalização do Programa, de acordo com as normativas estabelecidas pelo governo. Podem participar do PMM as prefeituras que manifestem interesse e apresentem pelo menos uma das seguintes caraterísticas: áreas afastadas com carência de médicos; vinte por cento ou mais da população em situação de alta vulnerabilidade social; população com mais de oitenta mil habitantes, com alta vulnerabilidade e renda per capita baixa; localização em área de atuação de Distrito Sanitário Indígena (DSEI/SESAI/MS); capital ou região metropolitana que tenha população em situação de alta vulnerabilidade. A relação dos municípios inscritos e selecionados está disponibilizada no Portal Saúde (BRASIL, 2014). É interessante destacar que a política é coordenada nacionalmente e que a principal contrapartida do município selecionado é fornecer moradia e alimentação para os médicos, bem como transporte para locais considerados de difícil acesso.

Os médicos participantes devem necessariamente passar por uma capacitação em instituição pública de ensino superior e recebem uma bolsa concedida pelo governo, que também é responsável pelas despesas com passagens para o médico e sua família. O governo deixa claro que o Programa não cria vínculos empregatícios e tem duração de três anos, podendo ser prorrogado por mais três e que é dado preferência aos médicos brasileiros formados em instituições brasileiras ou então com diploma revalidado no Brasil e que estejam em dia com a Justiça Eleitoral e, no caso de homens, com obrigações militares.

Médicos estrangeiros, doravante denominados intercambistas, podem concorrer a vagas não preenchidas por brasileiros, desde que apresente: diploma superior de instituição estrangeira; "habilitação para o exercício da medicina no exterior"; proficiência em língua portuguesa apresentada tanto no momento da inscrição quanto "após aprovação no curso de acolhimento", concentrado em oito capitais do país e com duração de quatro semanas (BRASIL, 2013b). 
Por último, o país do intercambista deve apresentar uma relação médico/habitante igual ou superior à do Brasil, qual seja, 1,8 médicos/mil habitantes. Cumprido os requisitos, o intercambista deve receber um registro único, emitido pelo Ministério da Saúde, que o torna habilitado para exercer a medicina no país. O número do registro, bem como informações pessoais, sobre o local de atuação e sobre o país de formação deve ser encaminhado ao CRM Conselho Regional de Medicina. Só então o médico é designado para assumir função no atendimento básico em município determinado, com carga horária de quarenta horas semanais.

Na avaliação realizada pelo Ministério da Saúde (BRASIL, 2015a, p. 6; 9), após um ano o PMM recrutou e alocou 14.462 médicos para a Atenção Básica, com cerca de 50 milhões de pessoas beneficiadas, em 3.785 municípios, sendo que mais de $75 \%$ dos médicos estão em municípios de alta vulnerabilidade social. Dos médicos estrangeiros que atuam no Programa, "11.429 são médicos cubanos que foram recrutados por meio de uma parceria entre o Ministério da Saúde do Brasil e a Organização Pan-Americana de Saúde e desta última com o Ministerio de Salud Pública de Cuba" (OLIVEIRA et al., 2015; BRASIL, 2015a).

Mas apesar dos resultados positivos divulgados pelo Ministério da Saúde as polêmicas a respeito do PMM continuam. Neste sentido, apresenta-se agora a alguns limites e potencialidades que se destacam no debate em torno do Programa.

\section{LIMITES E POTENCIALIDADES DO PROGRAMA MAIS MÉDICOS}

O PMM surge como uma resposta às necessidades de saúde da população brasileira. Uma resposta produzida socialmente e conduzida pelo Estado (CUNHA, CESSE e FONTBONNE, 2013) que visa atender ao disposto na Constituição Federal de 1988 (BRASIL, 1988), artigos 196 a 198, assegurando a universalidade do direito à saúde e "instituindo um sistema único que tem por escopo garantir ao indivíduo o acesso efetivo à saúde, através das políticas públicas elaboradas pelas entidades estatais" (DUARTE, 2013, p.78).

O desenho desta política de saúde merece algumas considerações a partir das fases do processo de políticas públicas (OLIVEIRA, 2013). Os problemas no SUS, principalmente os perceptíveis no atendimento básico, são conhecidos pelo governo. Mas foi o chamado clamor das ruas em 2013, que fez com que eles fossem de fato incorporados na agenda governamental.

Segundo Oliveira (2013), a construção da agenda é a primeira fase de uma política pública. A segunda fase, por sua vez, consiste na elaboração/formulação do Programa, intersetorial na sua confecção e na sua implementação, na medida em que envolveu uma parceria entre os Ministérios da Saúde e da Educação. É importante destacar que houve também um trabalho dos parlamentares, que analisaram e a MP 621/2013 para se tornar a Lei 12.871/2013, na fase do processo decisório. A implantação do Programa é a quarta fase do processo e envolve todos os entes federativos, embora a coordenação da política seja feita nacionalmente e a execução, no que diz respeito ao atendimento aos usuários do SUS, nos municípios. A avaliação é a fase que permite verificar se a política tem eficiência, eficácia e efetividade. Embora o Ministério da Saúde tenha realizado uma avaliação do PMM, ela é parcial e se remete ao processo de implantação.

$\mathrm{Na}$ construção e implementação do Programa, a exemplo do que ocorre com outras políticas públicas, diferentes atores exerceram papéis importantes. Os atores governamentais estão presentes nas diferentes fases do processo, da agenda à avaliação institucional, mas há também outros atores que precisam ser considerados, como grupos de pressão, acadêmicos, mídia, partidos políticos e opinião pública (OLIVEIRA, 2013, p.34). É interessante frisar que estes últimos alimentaram por assim dizer as polêmicas em torno do PMM.

As controvérsias em torno do Programa estão presentes constantemente na mídia, fomentando debates na sociedade, no meio acadêmico e entre os atores. Embora já tenha completado mais de dois anos de existência, os debates continuam acirrados. Por este motivo, é 
relevante a discussão a respeito de seus limites e potencialidades, de forma a subsidiar possíveis alterações ou adequações nesta política de saúde ou em outras ações com o mesmo objetivo.

Procuramos contribuir com essa discussão por meio da revisão sistemática realizada nos indexadores SCIELO e BIREME, no período de 2013 a outubro de 2015. Dos dezesseis artigos identificados, selecionamos nove para a discussão neste artigo, que possibilitaram a elaboração de dois quadros (Quadros 1 e 2) representativos dos limites e potencialidades do PMM.

Como é possível perceber no Quadro 1 (Limites do PMM), Campos (2013), Schanaider (2014) e Scheffer (2015) consideram que o aumento das vagas nos cursos de medicina deve gerar número excessivo de médicos, privilegiando a quantidade e não a qualidade dos graduados. $\mathrm{O}$ Programa incentiva a abertura de Faculdades de Medicina particulares com o intuito de suprir a falta de médicos, entretanto, o aumento de médicos formados no Brasil, por si só, não garante a resolução dos problemas no atendimento básico, tampouco resolve a distribuição desigual, pois não assegura a alocação destes no interior do país.

\section{QUADRO 1 - LIMITES DO PROGRAMA MAIS MÉDICOS}

\begin{tabular}{|c|c|}
\hline Limites & Autores \\
\hline $\begin{array}{l}\text { Médicos formados no Brasil - O aumento das vagas deve gerar número excessivo } \\
\text { de médicos, privilegiando a quantidade e não a qualidade, ademais não garante a } \\
\text { alocação destes no interior do Brasil. }\end{array}$ & $\begin{array}{l}\text { CAMPOS (2013) } \\
\text { SCHANAIDER (2014) } \\
\text { SCHEFFER (2015) }\end{array}$ \\
\hline $\begin{array}{l}\text { Falta de estrutura - Se houvesse estrutura e se todos os direitos trabalhistas } \\
\text { fossem respeitados, não faltariam profissionais em nenhum canto do Brasil. }\end{array}$ & $\begin{array}{l}\text { LOPES }(2013 a) \\
\text { CAMPOS }(2013)\end{array}$ \\
\hline $\begin{array}{l}\text { Médicos estrangeiros - As políticas de recrutamento de estrangeiros, baseadas na } \\
\text { melhor remuneração e no aperfeiçoamento profissional como fatores de atração, } \\
\text { ainda que permitam o ajustamento emergencial da oferta em áreas remotas, não } \\
\text { podem ser vistas como panaceia, pois a disponibilidade internacional de migração } \\
\text { de médicos atingiu certo limite. }\end{array}$ & $\begin{array}{l}\text { CAMPOS (2013) } \\
\text { SCHEFFER (2015) }\end{array}$ \\
\hline $\begin{array}{l}\text { Custo - Os incrementos financeiros são insuficientes, pois tal política tem custo } \\
\text { elevado, estimula a permanência provisória e não fixa médicos em médio e longo } \\
\text { prazo. }\end{array}$ & SCHEFFER (2015) \\
\hline $\begin{array}{l}\text { Formação - Profissionais formados fora do Brasil sem um exame para comprovar a } \\
\text { capacitação, e a criação de serviço civil obrigatório para os acadêmicos de } \\
\text { Medicina. }\end{array}$ & LOPES (2013b) \\
\hline $\begin{array}{l}\text { Duas medicinas - Criação de duas medicinas no Brasil, uma que se contenta com } \\
\text { médicos sem revalidação do diploma e outra com medicina de ponta. }\end{array}$ & LOPES (2013a, 2013b) \\
\hline $\begin{array}{l}\text { Atendimento clínico - Predomina nas políticas de Saúde Pública em nosso país o } \\
\text { equívoco de uma visão dominada por uma perspectiva médica com foco na doença } \\
\text { que, por sua vez, se reduz a ações direcionadas à cura através de medicamentos e } \\
\text { cirurgias. }\end{array}$ & RIBEIRO (2015) \\
\hline $\begin{array}{l}\text { Falta de capacitação - Falta capacitação para médicos que são destinados para } \\
\text { áreas específicas, indígenas por exemplo. Principalmente sobre a cultura e a língua } \\
\text { materna dos povos nativos, visto que esses grupos apresentam particularidades } \\
\text { tanto culturais quanto linguísticas. }\end{array}$ & SILVA et al (2015) \\
\hline
\end{tabular}

Na perspectiva de Campos (2013), Schanaider (2014) e Scheffer (2015) há inúmeras alternativas de trabalho mais compensadoras nos grandes centros. Schanaider (2014) defende que uma solução para esse problema seria a criação de uma carreira de Estado que incentive a redistribuição espacial dos médicos recém-formados, visando a renovação e a migração para grandes centros após um tempo de carreira no interior.

A falta de estrutura do SUS é outro ponto destacado como um limite do PMM. Para Lopes (2013a), o aumento do número de médicos é insuficiente para resolver os problemas da saúde no Brasil. Em seus argumentos deixa claro de que nada adianta aumentarmos o número de médicos se a estrutura oferecida pelo SUS aos profissionais (exames, medicamentos, instrumentos, equipe multidisciplinar) continua aquém das necessidades. Os médicos estrangeiros também são elencados no quadro dos limites do Programa. Campos (2013) e Scheffer (2015) apontam que a contratação desses profissionais tem limites e não pode ser entendida como a solução do problema, justamente pelo fato do PMM ser de ordem emergencial e com duração de

Revista de Direito Brasileira | São Paulo, SP | v. 17 | n. 7 | p. 291 - 305 | Mai./Ago. 2017 
três anos. As dúvidas em relação à formação destes médicos estrangeiros também são limitadoras e poderiam levar ao exercício de duas medicinas antagônicas no país, uma de ponta e outra de médicos sem revalidação de diploma. Assim, de acordo com Campos (2015, p. 642), é preciso que se pense em alternativas para a "baixa efetividade da gestão de pessoal do SUS (...) principal fator a dificultar recrutamento e qualificação do trabalho em saúde no Brasil”.

Por fim, outro fator limitador apontado pelos autores é o predomínio de "uma visão dominada por uma perspectiva médica com foco na doença" (RIBEIRO, 2015, p. 422), priorizando ações curativas em detrimento de ações preventivas. Este fator leva a outro que é a falta de capacitação de médicos das áreas indígenas, por exemplo, onde a própria concepção de saúde e doença é muito distinta. É claro que o médico precisa dominar as técnicas modernas de intervenção, mas também conhecer as peculiaridades linguísticas e culturais dos povos com os quais têm contato.

Resta destacar a questão do custo elevado desta política pública, na medida em que estimula a permanência provisória, pois não fixa os médicos em regiões consideradas carentes de profissionais. Nesse sentido, com base nos limites apontados pelos autores, é possível verificar que o PMM tangencia, mas não resolve o problema do gerenciamento e do subfinanciamento da Atenção Básica no Brasil.

No quadro 2 trabalhamos com as potencialidades do PMM destacadas pelos autores. De forma geral, os autores estudados destacam como positiva a preocupação com a formação de médicos para atuar na Atenção Básica (OLIVEIRA et al., 2015; NUNES, 2014; CAMPOS, 2013; SILVA et al., 2015).

QUADRO 2 - POTENCIALIDADES DO PROGRAMA MAIS MÉDICOS

\begin{tabular}{|c|c|}
\hline Potencialidades & Autores \\
\hline $\begin{array}{l}\text { Formação com estágio na Atenção Básica - Preocupação com a formação dos } \\
\text { médicos segundo métodos empregados em países com sistemas públicos de saúde, } \\
\text { no caso, aumentando estágio na atenção primária ou básica. }\end{array}$ & $\begin{array}{l}\text { CAMPOS (2013) } \\
\text { SILVA et al (2015) }\end{array}$ \\
\hline $\begin{array}{l}\text { Mais médicos - Recrutar uma parte dos médicos para a Atenção Básica segundo } \\
\text { normativas compulsórias ou estratégias de indução. }\end{array}$ & CAMPOS (2013) \\
\hline $\begin{array}{l}\text { Aumento na residência em áreas estratégicas - A ampliação, em torno de dez mil } \\
\text { novas vagas, para residência; Se forem priorizadas residências para médicos de } \\
\text { saúde da família e comunidade (generalistas, especializados em atenção primária) e } \\
\text { outros especialistas em falta no SUS: anestesistas, psiquiatras, oncologistas, } \\
\text { pediatras, entre outros. }\end{array}$ & $\begin{array}{l}\text { CAMPOS (2013) } \\
\text { OLIVEIRA et al (2015) } \\
\text { SILVA et al (2015) }\end{array}$ \\
\hline $\begin{array}{l}\text { Formação de Recursos Humanos para a saúde - formação orientada com o } \\
\text { propósito de que o Brasil disponha dos médicos de que necessita para a consolidação } \\
\text { do SUS, fundamentado na ABS/ESF. }\end{array}$ & $\begin{array}{l}\text { NUNES (2014) } \\
\text { SILVA et al (2015) } \\
\text { OLIVEIRA et al (2015) } \\
\end{array}$ \\
\hline $\begin{array}{l}\text { Atenção Básica em regiões carentes - Ao fixar médicos, por meio de provimento } \\
\text { emergencial, o projeto ampliou a assistência no atendimento básico em regiões } \\
\text { carentes desses profissionais. }\end{array}$ & $\begin{array}{l}\text { SILVA et al (2015) } \\
\text { OLIVEIRA et al (2015) }\end{array}$ \\
\hline $\begin{array}{l}\text { Médicos intercambistas - Formação acadêmica dos médicos intercambistas } \\
\text { apresenta diferenciais oportunos para o exercício da profissão no contexto das } \\
\text { comunidades indígenas. Dentre eles, destaca-se o conhecimento sobre plantas } \\
\text { medicinais. }\end{array}$ & SILVA et al (2015) \\
\hline
\end{tabular}

Através do PMM a formação de recursos humanos está sendo orientada para a ampliação do número de médicos com atuação na Atenção Básica. Isso se dá por meio de recrutamento compulsório de médicos ou estratégias de indução utilizadas pelo PMM ${ }^{17}$. Ao fixar médicos, por meio de provimento emergencial, o projeto ampliou a assistência no atendimento básico em regiões carentes desses profissionais, de acordo com a Organização Pan-Americana da Saúde (BRASIL, 2015b).

É interessante também o destaque que Campos (2013), Oliveira et al (2015) e Silva et al (2015) dão para o aumento de vagas na residência médica, especialmente na saúde da família, generalistas e em áreas que faltam profissionais no SUS, como a pediatria, por exemplo. Esse 
aumento, podemos dizer, deixa claro o intuito dessa política em valorizar a saúde pública e melhorar a qualidade na Atenção Básica.

Outra potencialidade apontada pelos autores pesquisados é que a formação diferenciada dos médicos intercambistas tem favorecido o exercício da medicina em comunidades indígenas. Isso é demonstrado pelo conhecimento sobre plantas medicinais, por exemplo (SILVA, et al., 2015).

Por fim, pode-se afirmar que os autores selecionados concordam que o Programa prioriza e valoriza medidas emergenciais que asseguram a ampliação e a garantia de médicos generalistas, especializados em Atenção Básica, em áreas deficitárias e vulneráveis. Em outros termos, defendem que o PMM resolve, a curto prazo, as desigualdades no acesso ao SUS, principalmente no que se refere ao atendimento primário.

\section{CONCLUSÃO}

O PMM foi criado pelo governo federal com o intuito de facilitar o acesso à Atenção Básica em todas as localidades, de modo a diminuir as desigualdades regionais e garantir a efetivação do princípio da Universalidade, tão propagado pelo SUS. Após dois anos de implantação, uma avaliação institucional do Programa ainda não foi realizada a contento, pelo próprio curto tempo de implementação. Mas o Ministério da Saúde (BRASIL, 2015a) apresentou um relatório com dados referentes ao primeiro ano do PMM. Nele, destaca que o Programa recrutou e alocou 14.462 médicos em 3.785 municípios, sendo que 1.846 são brasileiros e 12.616 são estrangeiros de 49 países. Todavia, dos profissionais estrangeiros, intercambistas, a maioria (11.429) é cubana, recrutada por meio de uma parceria Ministério da Saúde e Organização PanAmericana de Saúde e Ministerio de Salud Pública de Cuba.

Sublinhamos que esse dado por si só, gerou muita polêmica e foi amplamente debatido pela mídia que fez, nas palavras de Oliveira (2013), uma "avaliação não institucional" da política. Como se deu esse processo, contudo, foge ao escopo deste trabalho e pode ser objeto de uma nova pesquisa.

A academia não se furtou a entrar na discussão e também procurou e procura realizar estudos sobre esta política de saúde. Neste trabalho verificamos que os limites do PMM apontados pelos autores pesquisados demonstram certa preocupação com a repercussão destas medidas a longo prazo, tanto no que diz respeito à formação e contratação dos médicos, como no suporte financeiro que o Programa exige. As potencialidades do PMM, por sua vez, passam pela valorização de políticas governamentais preocupadas em efetivar medidas que assegurem a ampliação e a garantia de médicos generalistas para a Atenção Básica, em áreas deficitárias. Por fim, o confronto das potencialidades do PMM e de seus limites pode contribuir com o processo de avaliação deste Programa de Governo, que visa, em linhas gerais, melhorar o atendimento primário na saúde pública brasileira.

\section{REFERÊNCIAS BIBLIOGRÁFICAS}

BAHIA. Diretoria de Atenção Básica do Governo do Estado da Bahia. Programa Mais Médicos. Disponível em

http://www.saude.ba.gov.br/dab/index.php?option=com_content \&view=article\&id=687\&Itemid= 318. Acesso em 23 out. 2015.

BRASIL. Medida Provisória nº 621, de 08 de julho de 2013a. Institui o Programa Mais Médicos e dá outras providências. Disponível em:

http://www.camara.gov.br/proposicoesWeb/fichadetramitacao?idProposicao $=584020$ Acesso em 07 mai. 2014. 
BRASIL. Ministério da Saúde. Apresentação de um ano do Programa Mais Médicos. Disponível em: <http://portalsaude.saude.gov.br/images/pdf/2014/setembro/04/apresentacao-COLETIVA-1ANO-MAIS-M--DICOS---04-09-1.pdf Acesso em 16 set. 2015a.

BRASIL. Ministério da Saúde. Programa Mais Médicos. Portal da Saúde. Disponível em: http://portal.saude.gov.br/portal/saude/cidadao/default.cfm> Acesso em 07 mai. 2014.

BRASIL. Organização Pan-Americana da Saúde. Nota da OPAS/OMS no Brasil sobre o Projeto Mais Médicos. 2015b. Disponível em:

http://www.paho.org/bra/index.php?option=com_content\&view=article\&id=4798:nota-daopasomsno-brasil-projeto-mais-medicos\&catid=1274:programa-especial-mais$\underline{\text { Medicosnoticias\&Itemid=827 }}$. Acesso em 15 out. 2015.

BRASIL. Portal Brasil. Médicos cubanos chegam às capitais nesta segunda. 9 nov. 2013c. Disponível em http://www.brasil.gov.br/saude/2013/11/medicos-cubanos-chegam-as-capitaisnesta-segunda-feira-11. Acesso em 23 out. 2015

BRASIL. Presidência da República. Constituição da República Federativa do Brasil de 1988. Disponível em: http://www.planalto.gov.br/ccivil_03/constituicao/ConstituicaoCompilado.htm Acesso em 11 nov. 2015.

BRASIL. Presidência da República. Lei n. 12.871 de 22 de outubro de 2013b. [acessado em 2015 Out 15]; Disponível em: http://www.planalto.gov.br/ccivil_03/_ato20112014/2013/Lei/L12871.htm Acesso em 15 out. 2015.

CAMPOS, F.E.; MACHADO, M.H.; GIRARDI, S.N. A fixação de profissionais de saúde em regiões de necessidades. Divulgação e Saúde para Debate. n.44, p.3-24, 2009. Disponível em: http://www.cnts.org.br/public/arquivos/Artigo_Campos.pdf. Acesso em 16 set. 2015.

CAMPOS, G.W.S. A Saúde, o SUS e o programa "Mais Médicos". Rede HumanizaSUS. 17 jul. 2013. Disponível em: http://www.redehumanizasus.net/63816-a-saude-o-sus-e-o-programa-maismedicos Acesso em 05 mai. 2015.

CAMPOS, G.W.S. Mais médicos e a construção de uma política de pessoal para a Atenção Básica no Sistema Único de Saúde (SUS). Interface (Botucatu). v. 19, n.54, p. 641-642, 2015. Disponível em: http://www.scielo.br/scielo.php?script=sci_arttext\&pid=S1414-

$\underline{32832015000300641 \& \operatorname{lng}=\mathrm{en}}$. http://dx.doi.org/10.1590/1807-57622015.0286 . Acesso em 24 mai. 2016.

CUNHA, N.M.; CESSE, E.A.P.; FONTBONNE, A. A política de saúde no Brasil e a hipertensão arterial sistêmica (HAS) na ótica do direito à saúde: fragilidades e desafios. In: Oliveira M HB et al. Direito \& Saúde. Cidadania e ética na construção de sujeitos sanitários. Maceió: Edufal; 2013.

CYRINO, E.G. et al. O Programa Mais Médicos e a formação no e para o SUS: por que a mudança? Esc. Anna Nery. Mar., v. 19, n. 1, p. 5-6, 2015. Disponível em: http://www.scielo.br/scielo.php?script=sci arttext\&pid=S1414-81452015000100005\&lng=pt . http://dx.doi.org/10.5935/1414-8145.20150001 .Acesso em 24 mai. 2016. 
DEMOGRAFIA Médica No Brasil. São Paulo: CREMESP/CFM, 2011. Disponível em: http://www.cremesp.org.br/pdfs/demografia_2_dezembro.pdf. Acesso em 03 mar.2016.

DUARTE, L.G.M. Eficácia do direito social à saúde. Revista Ética e Filosofia Política. JUn. v. 1, n.16, p. 77-105, 2013. Disponível em:

http://www.ufjf.br/eticaefilosofia/files/2009/08/16_1_melquiades.pdf. Acesso em 11 nov. 2015.

GABRIEL, L. Governo autoriza 2.290 vagas de medicina em faculdades privadas. Portal G1 Educação. 10 jul. 2015. Disponível em http://g1.globo.com/educacao/noticia/2015/07/governovai-abrir-2290-mil-vagas-de-medicina-em-faculdades-privadas.html Acesso em 06 mar. 2016

LOPES, A.C. "Programa Mais Médicos" e a Saúde no Brasil. Rev Soc Bras de Clin Méd, v.11, n.4, 2013b. Disponível em http://www.sbcm.org.br/revistas/RBCM/RBCM-2013-04.pdf. Acesso em 05 mai. 2015.

LOPES, A.C. Mais médicos ou mais saúde? Jornal o Cruzeiro do Sul. 25 set. 2013a; Disponível em: http://www.jornalcruzeiro.com.br/materia/504354/mais-medicos-ou-mais-saude . Acesso em 05 mai. 2015.

NUNES F. Influência do Programa Mais Médicos nos indicadores de Saúde. Centro Brasileiro de Estudos de Saúde - CEBES. 2014. Disponível em: http://cebes.org.br/2014/09/influencia-doprograma-mais-medicos-nos-indicadores-de-saude/. Acesso em 05 mai. 2015.

OLIVEIRA, F.P. et al. Mais Médicos: um programa brasileiro em uma perspectiva internacional. Interface (Botucatu). v. 19, n. 54,p. 623-634, 2015. Disponível em: http://www.scielo.br/scielo.php?script=sci_arttext\&pid=S1414-32832015000300623\&lng=en. http://dx.doi.org/10.1590/1807-57622014.1142. Acesso em 24 mai. 2016.

OLIVEIRA, V.E. As fases do processo de políticas públicas. In: Marchetti V (Org). Políticas Públicas em debate. São Bernardo do Campo: ABCD Maior, UFABC, 2013.

RIBEIRO, R.C. Programa Mais Médicos: um equívoco conceitual. Ciênc. saúde coletiva . v. 20, n. 2, p.421-424, 2015. Disponível em: http://www.scielo.br/scielo.php?script=sci_arttext\&pid=S1413-81232015000200421\&lng=en . http://dx.doi.org/10.1590/1413-81232015202.00812014 .Acesso em 24 mai. 2016.

SCHANAIDER, A. Mais ou menos médicos! Rev. Col. Bras. Cir. v. 41, n. 5, p. 303-304, 2014.

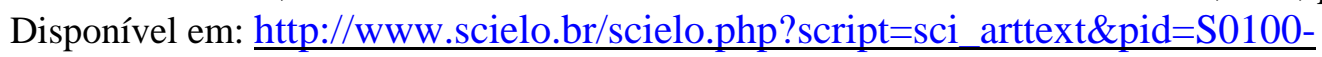
$\underline{69912014000500303 \& \operatorname{lng}=\mathrm{en}}$. http://dx.doi.org/10.1590/0100-69912014005001 .Acesso em 24 mai. 2016.

SCHEFFER, M. et al. Demografia Médica no Brasil. São Paulo: CREMESP/CFM. 2015. Disponível em: http://www.flip3d.com.br/web/pub/cfm/index10/?numero=12. Acesso em 05 mar. 2016. 
SCHEFFER, M. Programa Mais Médicos: em busca de respostas satisfatórias. Interface (Botucatu). v.19, n. 54, p. 637-670, 2015. Disponível em:

http://www.scielo.br/scielo.php?script=sci_arttext\&pid=S1414-32832015000300637\&lng=en

. http://dx.doi.org/10.1590/1807-57622015.0245. Acesso em 24 mai. 2016.

SILVA, R.P. et al. A experiência de alunos do PET-Saúde com a saúde indígena e o programa Mais Médicos. Interface (Botucatu) v. 19( Suppl 1): 1005-1014, 2015. Disponível em: http://www.scielo.br/scielo.php?script=sci_arttext\&pid=S1414-32832015000501005\&lng=en . http://dx.doi.org/10.1590/1807-57622014.1021 Acesso em 24 mai. 2016. 